\title{
Toxicity mitigation by $\mathrm{N}$-acetylcysteine and synergistic toxic effect of nano and bulk $\mathrm{ZnO}$ to Panagrellus redivivus
}

\author{
Lola Virág Kiss ${ }^{1}$ (D) $\cdot$ Zoltán Sávoly $^{2} \cdot$ András Ács $^{3} \cdot$ Anikó Seres $^{1} \cdot$ Péter István Nagy ${ }^{1}$
}

Received: 19 October 2020 / Accepted: 22 January 2021 / Published online: 2 March 2021

(C) The Author(s) 2021

\begin{abstract}
To better understand the nanosize-relevant toxic effects and underlying mechanisms, $N$-acetylcysteine (NAC), as a mitigation agent, an ionic form of $\mathrm{Zn}\left(\mathrm{ZnCl}_{2}\right)$, and the binary mixture of $\mathrm{ZnO}$ with different particle sizes (15 nm and $\left.140 \mathrm{~nm}\right)$, was used in toxicity assays with the nematode Panagrellus redivivus. The $\mathrm{ZnCl}_{2}$ concentrations were applied to show the amount of dissolved $\mathrm{Zn}$ ions present in the test system. Reactive oxygen species (ROS) measuring method was developed to fit the used test system. Our studies have shown that NAC can mitigate the toxic effects of both studied particle sizes. In the applied concentrations, $\mathrm{ZnCl}_{2}$ was less toxic than both of the $\mathrm{ZnO}$ particles. This finding indicates that not only ions and ROS produced by the dissolution are behind the toxic effects of the ZnO NPs, but also other particle size-dependent toxic effects, like the spontaneous ROS generation, are also relevant. When the two materials were applied in binary mixtures, the toxic effects increased significantly, and the dissolved zinc content and the ROS generation also increased. It is assumed that the chemical and physical properties of the materials have been mutually reinforcing to form a more reactive mixture that is more toxic to the $P$. redivivus test organism. Our findings demonstrate the importance of using mitigation agent and mixtures to evaluate the sizedependent toxicity of the $\mathrm{ZnO}$.
\end{abstract}

Keywords Zinc-oxide $\cdot N$-acetylcysteine $\cdot$ Interaction $\cdot$ Nanomaterial $\cdot$ Nematode $\cdot$ Synergistic

\section{Introduction}

The prevalent use of nanotechnology in each part of human life results in an immense release of engineered nanomaterials to the environment. Some metal-based nanomaterials like zinc oxide $(\mathrm{ZnO})$ reached significant importance for their extensive commercial applications. According to Coll et al. (2016) and Kiss et al. (2020), $\mathrm{ZnO}$ is the nanomaterial of the greatest concern because of its exhibited high toxicity and predicted exposure concentrations.

Responsible Editor: Ludek Blaha

Lola Virág Kiss

lolavirag.kiss@gmail.com

1 Department of Zoology and Animal Ecology, Szent István University, Gödöllö, Hungary

2 Budapest, Hungary

3 Department of Aquaculture, Institute for Conservation of Natural Resources, Faculty of Agricultural and Environmental Sciences, Szent István University, Gödöllő, Hungary
After being released to the soil environment, $\mathrm{ZnO}$ NPs (zinc-oxide nanoparticles) can be adsorbed onto soil particles, react with organic materials, and even be transported to groundwater. As a result of its increasing released amounts (Gottschalk et al. 2009, Sun et al. 2016) and its potential leaking into pore water, $\mathrm{ZnO}$ can pose a risk to soil microfauna, including nematodes. Soil living nematodes are highly exposed to $\mathrm{ZnO} \mathrm{NP}$ pollution in the environment. There is vast evidence in the scientific literature showing that $\mathrm{ZnO}$ NPs are toxic in the applied concentrations (Ma et al. 2011, Wu et al. 2013, Khare et al. 2014, Sávoly et al. 2016, Kiss et al. 2018). Several studies observed significant mortality trends for various nematode species at concentrations as low as $0.32-0.65 \mathrm{mg} / \mathrm{l}$ (Khare et al. 2011, Kiss et al. 2018). Nanosize-relevant toxicity varied from laboratory to laboratory. Different test methods and the physical and chemical differences in the materials used may have been lied behind that. In most of the cases, however, ZnO NPs with smaller particle size were more toxic (Ma et al. 2011, Khare et al. 2011). Freeliving soil nematodes are part of the food chain, are involved in degradation and remediation processes and have great importance in the global biogeochemical cycles of various 
substances (Vinciguerra 1979, Sochová et al. 2006). Therefore, it is crucial to investigate the effects on soil nematodes exposed directly to $\mathrm{ZnO} \mathrm{NPs}$, preferably in the most environmentally relevant test medium.

Due to their varied applicability, the release of ZnO NPs is expected to increase, despite the vast amount of data available on potential hazards and risks, making reducing the toxic effects of $\mathrm{ZnO}$ NPs a paramount task. A suitable method is to mitigate or even eliminate the negative effects in a way that beneficial properties are maintained, with the help of various mitigating agents. The $\mathrm{N}$-acetylcysteine (NAC) antioxidant can be suitable for this task because NAC is considered an important antioxidant and free radical scavenger by increasing intracellular glutathione levels (Sun 2010) and downregulating AP-1 luciferase activity (Shi et al. 2017). Moreover, thiol groups in NAC reduce free radicals and also provide the chelating site for metals (Flora and Pachauri 2010). Due to these abilities, NAC has been widely used in several research fields for investigating the toxic effects of ZnO NPs (Ma et al. 2014, Wang et al. 2014, El-Shorbagy et al. 2019). Toxicity mitigation effects were successfully observed in the relation of nematodes tested with $\mathrm{TiO}_{2} \mathrm{NPs}$ (Wu et al. 2012, 2013), $\mathrm{Al}_{2} \mathrm{O}_{3}$ NPs (Li et al. 2012), and also ZnO NPs (Wu et al. 2013). Reports about the environmental effects of NAC are quite scarce, and its effect on the biota is relatively unknown. No safety concerns were described in human and animal studies collected in Bhatti et al.'s (2018) review about the topic. Moreover, they reported reduced apoptosis and oxidative stress. However, NAC can be overdosed and cause severe health problem such as hemolysis, thrombocytopenia, and death (Mahmoudi et al. 2015). NAC also have antibacterial properties; it is able to disperse biofilms of both Gramnegative and Gram-positive bacteria (Nowacka et al. 2018).

The $\mathrm{ZnO}$ NP toxicity can result from multiple properties, including photo-induced and regular dissolution of zinc ions, generation of reactive oxygen species (ROS), and other potential particle-specific effects like direct contact between the particles and the cells of an organism (Brunner et al. 2006, Khare et al. 2014, Starnes et al. 2019). Moreover, size relevant effects of $\mathrm{ZnO}$ nanoparticles (NPs) and excess release of $\mathrm{Zn}^{2+}$ can also result in the generation of ROS. Even so, most studies point to $\mathrm{ZnO}$ NPs dissolution to ionic $\mathrm{Zn}$ playing the most significant role in eliciting toxicity (Ma et al. 2014, Wang et al. 2016, Sávoly et al. 2016, Lead et al. 2018).

The wide use of diverse engineered nanomaterials can also lead to the release of different mixtures of nanomaterials into the environment. However, little is known about the combined toxicity of various nanomaterials (Mott et al. 2007, Jafari et al. 2011, Li et al. 2011, Tong et al. 2014, 2015). No information was found on the combined toxicity of $\mathrm{ZnO}$ NPs and its bulk form, although exposure to such a complex is a realistic scenario as well. Furthermore, experiments dealing with a mixture of differently sized nanomaterials can also elucidate the size relevant effects of them.

In the present study, the main aim was to better understand the size relevant toxic effects of the $\mathrm{ZnO}$ on the nematode Panagrellus redivivus and mechanisms behind them. The usage of a mitigation agent, an ionic form of $\mathrm{Zn}$, and a binary mixture of two $\mathrm{ZnO}$ agents with different sizes helped to explore size-dependent toxicity of the $\mathrm{ZnO}$ particles. In this research, we hypothesized that the nano-relevant toxic effects could be identified through mitigation assays with NAC, as it influences both the ionic and the ROS induced toxicity. It was assumed that $\mathrm{ZnCl}_{2}$ in the concentration series set by the dissolution rate of the $\mathrm{ZnO}$ compounds could elucidate the role of ionic toxicity in the toxicity mechanism of $\mathrm{ZnO}$ NPs. Furthermore, we hypothesized that the environmentally relevant combination of nano and bulk $\mathrm{ZnO}$ particles (15 and 140 $\mathrm{nm}$ ) has different effects on used test species as compared with the same particles applied separately. For the aim of better clarifying the difference between compound effects, combined toxicity was also tested with the addition of NAC. In addition, we developed a technique to measure ROS production in a way that fits to the test system we used.

\section{Materials and methods}

\section{Particle size characterization and sample preparation}

Two $\mathrm{ZnO}$ particles of different nominal particle sizes were applied as (i) $10-30 \mathrm{~nm}$ (referred to as $15 \mathrm{~nm}$ average particle size) with purity $99+\%$ and (ii) $80-200 \mathrm{~nm}$ (referred to as 140 average particle size) $\mathrm{ZnO}$ with purity $99.9+\%$. Both materials were purchased from US Research Nanomaterials, Inc. The particle shape of the $15 \mathrm{~nm} \mathrm{ZnO}$ was nearly spherical, and that of the $140 \mathrm{~nm} \mathrm{ZnO}$ was irregular. $\mathrm{ZnCl}_{2}$ was used as a free ionic positive control. For the mitigation experiments, $\mathrm{N}$ acetylcysteine (NAC) was the mitigation agent. Both $\mathrm{ZnCl}_{2}$ and NAC were purchased from Sigma-Aldrich.

The primary particle size and particle morphology were measured by scanning electron microscopy (SEM, FEI Quanta 3D, Eötvös Loránd University, Hungary). The materials were examined individually in previous experiments (Kiss et al. 2018). Both $\mathrm{ZnO}$ compounds contained nano and bulk particles; however, based on the definition of nanomaterials - the particle size of at least half of the particles in the number size distribution must measure $100 \mathrm{~nm}$ or below-the $15 \mathrm{~nm}$ was in nanosize range and the $140 \mathrm{~nm}$ was in bulk size range (Kiss et al. 2018). Images were recorded from the binary mixture of the two, and the average size and size distribution were ascertained by measuring approximately 100 particles from representative images by the ImageJ 
software package. The $\mathrm{ZnO}$ particles were also checked with the addition of $N$-acetylcysteine after $24 \mathrm{~h}$ incubation by SEM.

New stock suspensions were made from the 15 and $140 \mathrm{~nm}$ and the binary mixture of them (referred to as Mix or mixture) (160.64 $\mathrm{mg} \mathrm{Zn/l)} \mathrm{and} \mathrm{ZnCl}_{2}(67.68 \mathrm{mg} \mathrm{Zn} / \mathrm{l})$ powders with Milli-Q water before each experiment. The mixture contained an equal amount (50-50\%) of $\mathrm{ZnO}$ particles with an average size of 15 and $140 \mathrm{~nm}$, respectively. The stock suspensions were dispersed by sonication for $20 \mathrm{~min}$ every time. Tested concentrations were chosen based on our previous experiments (Kiss et al. 2018). Environmentally relevant concentration of ZnO NPs was about 1.52-21 $\mu \mathrm{g} / \mathrm{l}$ in 2016 (Sun et al. 2016); however, this value is increasing day by day due to the huge amount of released $\mathrm{ZnO}$ NPs to the environment. The concentration series were prepared from the stock immediately after sonication and added to the test media. They were set up based on pre-tests of our research group. No lethal effects were observed in the environmentally relevant concentration range, so higher values were used to get the desirable effects.

\section{Dissolution of $\mathrm{ZnO}$ nanoparticles}

The dissolution of materials in Milli-Q water (from $5 \mathrm{ml}$ stock, $10.4 \mathrm{mg} \mathrm{Zn} / \mathrm{l}$ ) after $24 \mathrm{~h}$ of incubation time in a dark thermostat chamber was evaluated by centrifugation, followed by chemical analysis of complex supernatant zinc using inductively coupled plasma atomic emission spectrometry (ICPAES, Horiba Jobin-Yvon Activa-M, SZIE, Hungary) (Ma et al. 2014). Dissolution was assessed for pure 15, $140 \mathrm{~nm}$, mixture, and with the addition of NAC with all the mentioned compounds. Zn particles held in a complex by NAC were also included in the measurement.

\section{The mitigation effect of $\mathrm{N}$-acetylcysteine and toxicity of $\mathrm{ZnCl}_{2}$ compared with $\mathrm{ZnO}$ NPs on Panagrellus redivivus}

To facilitate the evaluation of results, an easily and quickly operated test system was chosen: a dose-response study with a bacterivore nematode, Panagrellus redivivus. $P$. redivivus can be found in a variety of nutrient-rich habitats such as soil, rotting fruits, insects, wheat paste, or beer yeast. It is an excellent species for studying the toxic effects of nanomaterials being easy to work with, having a high reproduction rate, and showing relatively minor differences from Caenorhabditis elegans, the most commonly used nematode species, in cell lineage (Sternberg and Horvitz 1982).

Toxicity assays were carried out based on modifications prompted by previously published methods (Ma et al. 2014, Hrács et al. 2018, Kiss et al. 2018). In a 96-well microplate (Bioster S.p.A., Italy), 5 adult nematode females were placed in each unit for testing acute mortality in Milli-Q water test media. The tests were performed with pure nano, bulk $\mathrm{ZnO}$ particles and $\mathrm{ZnCl}_{2}$, and with added NAC ( $5 \mathrm{mg} / \mathrm{l}$ concentration). The used NAC concentration was based on previous research of Ma et al. (2014) and Wu et al. (2013). Applied concentrations for $\mathrm{ZnO}$ and $\mathrm{ZnCl}_{2}$ compounds were 0.32 , $0.63,1.26,2.51,5.02$, and $10.04 \mathrm{mg} \mathrm{Zn} / 1$ and $0.13,0.26$, $0.53,1.06,2.12$, and $4.23 \mathrm{mg} \mathrm{Zn} / 1$, respectively. The $\mathrm{ZnCl}_{2}$ concentrations were set up based on the measured mean dissolution rate. Four replicates for each concentration and control were applied. Furthermore, a negative control $(320 \mu \mathrm{l}$ Milli-Q water) and a positive control containing NAC (160 $\mu \mathrm{l}$ Milli-Q water and $160 \mu \mathrm{l}$ NAC suspension) were also set up.

A group of animals was randomly sampled from the stock culture into a counter filled with Milli-Q water for pure toxicity assay or filled with $10 \mathrm{mg} / 1 \mathrm{NAC}$ suspension for mitigation assay. From here, female specimens were selected with a pipette. Females are usually bigger and more frequent than males. The females' vulva opening is located in the midline of the abdominal side, while the male orifice is located at the posterior end of the body, where the short, bent mating spike (spicule) can be easily recognized. Before the placement of the animals, $100 \mu \mathrm{l}$ of Milli-Q water or NAC solution $(10 \mathrm{mg} / \mathrm{l}$ concentration) was pipetted onto microplates to create a wet environment. Animals were then relocated with $2 \times 30 \mu \mathrm{l}$ Milli-Q water or NAC suspension into each well. Since the wells contained liquid by the time the solutions were added, the solutions with twofold concentrations were prepared before the experiments. After that, $160 \mu \mathrm{l}$ of the test solution or Milli-Q water, in the case of the control group, was added to the test system to reach the final amount of $320 \mu \mathrm{l}$ liquid. This way, the achieved final concentration of NAC was $5 \mathrm{mg} / \mathrm{l}$. The microplates were incubated in a thermostat chamber under dark conditions at $20 \pm 1{ }^{\circ} \mathrm{C}$. Surviving specimens were counted after $24 \mathrm{~h}$ under a transmission stereomicroscope (Olympus SZH 10).

\section{Interaction between $\mathrm{ZnO}$ nanoparticles}

The $P$. redivivus acute mortality test was used in the experiments investigating the interaction between nano and bulk $\mathrm{ZnO}$ particles. The concentration series were made from the $50-50 \%$ mixture of $\mathrm{ZnO}$ particles with an average size of $15 \mathrm{~nm}$ and $140 \mathrm{~nm}$. Experiments were carried out the same way as described in "The mitigation effect of $N$-acetylcysteine and toxicity of $\mathrm{ZnCl}_{2}$ compared with $\mathrm{ZnO} \mathrm{NPs}$ on Panagrellus redivivus." In preliminary experiments, only the three highest concentrations $(2.51 ; 5.02$ and $10.04 \mathrm{mg} / 1 \mathrm{Zn})$ were tested on their own and also with the addition of NAC to see if a valid result can indeed be obtained. Since there was a great difference between the toxicity of the mixture and that of the original substances, mainly with the addition of NAC, the entire experiment was repeated using the whole concentration series $(0.32,0.63 ; 1.26 ; 2.51 ; 5.02$ and $10.04 \mathrm{mg} / \mathrm{l} \mathrm{Zn})$. After 
$24 \mathrm{~h}$ of incubation, the microplate was examined under a stereomicroscope. Milli-Q water was used as a negative control.

\section{Measuring the intracellular reactive oxygen species generation}

Intracellular ROS production was measured using aminophenyl fluorescein (APF; Thermo Fisher) assay. APF is a relatively new and more specific indicator for ROS measurement than the hitherto used dyes (such as $2^{\prime}, 7^{\prime}$ dichlorodihydrofluorescein diacetate). It is more tolerant of light-induced oxidation and becomes fluorescent in the presence of hydroxyl radical ( $\mathrm{OH} \cdot)$, peroxynitrite anion (ONOO-), and hypochlorite anion $\left(\mathrm{OCl}^{-}\right)$(Nagano 2009). APF reacts three times more strongly to hydroxyl radicals than to other ROS radicals, e.g., superoxide $\left(\cdot \mathrm{O}_{2}{ }^{-}\right)$, hydrogen peroxide $\left(\mathrm{H}_{2} \mathrm{O}_{2}\right)$, or singlet oxygen $\left({ }^{1} \mathrm{O}_{2}\right)$ (Setsukinai et al. 2003). Several studies have suggested that the photocatalytic and antibacterial properties of nanoparticle oxides are mainly due to free and surface-bound hydroxyl radicals, although superoxide and hydrogen peroxide play a vital role in the processes (Ma et al. 2013). Thus, we can assume that $\mathrm{OH}$. production is a representative of total ROS formation by ZnO NPs.

No standard guideline is available for measuring intracellular ROS with APF. Therefore, a modified method was used based on other ROS measuring methods (Wang et al. 2018, Sarasija and Norman 2018, Yoon et al. 2018). In those studies, Caenorhabditis elegans was the tested nematode species. The two different nematode species length is almost the same (approx. $1 \mathrm{~mm}$ ). The diameter for $P$. redivivus on average is $50 \mu \mathrm{m}$ (Sautter et al. 2007), while for C. elegans, it can vary between 45 and $80 \mu \mathrm{m}$ (Maguire et al. 2011, Palikaras and Tavernarakis 2013, Desta et al. 2017). Therefore, P. redivivus was an adequate choice to replace $C$. elegans in this experiment. The measurement was set up similarly to the toxicity assay except the exposure time being only $3 \mathrm{~h}$, and for all six types of compounds, three concentrations were tested: 2.51 , 5.02, and $10.04 \mathrm{mg} \mathrm{Zn/1} \mathrm{(in} \mathrm{Milli-Q} \mathrm{water).} \mathrm{Instead} \mathrm{of} \mathrm{the} \mathrm{96-}$ well microplate, the test compounds were placed inside Eppendorf tubes to ensure the proper recovery of the nematode samples. After the incubation time, all replicates from one treatment were put into one tube (40 individuals/tube). Worms were suspended in $1.5 \mathrm{ml}$ phosphate-buffered saline buffer (100 mM PBS, pH 7.2), the tubes were centrifuged at $600 \times \mathrm{g}$ for $5 \mathrm{~min}$, and then the PBS was aspirated out. Only $80 \mu \mathrm{l}$ liquid was left inside the tubes with the animals. Subsequently, from the previously prepared APF stock (10 $\mu \mathrm{M}$ in PBS), $160 \mu \mathrm{l}$ was immediately added to the samples. Worms were then homogenized for 2 min (Qiagen TissueLyser LT). Homogenates were centrifuged for $12 \mathrm{~min}$ at $17,000 \times g$ to separate the worm lysate from the carcass pellet (Qhaus Fe5718R). First, the protein concentration was determined from $30 \mu \mathrm{l}$ solution $(10 \mu \mathrm{l}$ worm lysate $+20 \mu \mathrm{l}$ APF stock) using the Bradford Assay following manufacturer's instructions.

After that, for measuring the fluorescence, two replicates were used per treatment. Exposure was conducted in 96-well black microplate for the APF test. Seventy-five microliters of solution ( $25 \mu \mathrm{l}$ worm lysate and $50 \mu \mathrm{l}$ APF stock) was supplemented with $25 \mu \mathrm{l}$ PBS to reach $100 \mu \mathrm{l}$ per well. As for the blank (50 $\mu \mathrm{l}$ PBS) and the positive control $\left(50 \mu \mathrm{H} \mathrm{H}_{2} \mathrm{O}_{2}, 50\right.$ $\mathrm{mM}), 50-50 \mu \mathrm{APF}$ was added to each replicate. This method required an incubation of $30 \mathrm{~min}$ before the reading (dark condition, $37^{\circ} \mathrm{C}$ ). The samples were read at $490 \mathrm{~nm}(\mathrm{Ex}) /$ $515 \mathrm{~nm}(\mathrm{Em})$ on a microplate reader (Thermo Scientific Varioskan Lux). Measured ROS values were normalized to the mean value of the control of the given treatment. These values were also used when performing statistical analyses.

\section{Data analysis}

Median lethal and effective concentrations $\left(\mathrm{LC}_{50}, \mathrm{EC}_{50}\right)$ and associated confidence intervals $(95 \% \mathrm{CI})$ were calculated by Probit analysis using the ToxRat program (Light Version 2.08) (TOXRATLIGHT2.08 n.d.). This was repeated with the Microsoft Excel Solver plug-in to verify the results (Microsoft Corporation 2010). For the statistical analysis, R Statistics 3.5.2. program was used (RCoreTeam 2013). In those experiments where assumptions were met (balanced standard deviation, normal distribution), the $p$ values were calculated by one-way and two-way ANOVA $(F)$ with Tukey's honestly significant difference $(t)$ post hoc test. If the conditions were not met, linear model (LM) was used when examining the relationship of concentrations to control. For comparing different curves, generalized least squares (GLS) technique and, in some cases, an interactional linear model (ILM) were used. The GLS model can also be used well for unequal variances. Normality was checked in all cases with the Shapiro-Wilk test.

\section{Results}

\section{Particle characterization by SEM}

The average size for the mixture, based on measuring the diameter of 100 particles, was $130 \pm 118 \mathrm{~nm}(n=100)$. As revealed by looking at the mixture size distribution (Fig. 1e), the most common particle size by mode is $30 \mathrm{~nm}$, but also larger aggregates $(877 \mathrm{~nm})$ may be present. In addition, as the picture clearly shows, both forms (spherical, irregular) are present in samples (Fig. 1c, d). The binary mixture of $15 \mathrm{~nm}$ and $140 \mathrm{~nm} \mathrm{ZnO}$ individually and all three materials $(15 \mathrm{~nm}$, $140 \mathrm{~nm}$, binary mixture) were investigated with $\mathrm{N}$ acetylcysteine (Fig. 1). The addition of NAC did not 
Fig. 1 SEM images of the research compounds with NAC (15 nm ZnO (a), $140 \mathrm{~nm} \mathrm{ZnO}$ (b)). SEM images of a 50-50\% mixture of the two test substances individially (c) and with NAC (d). Size distribution of the mixture (e)
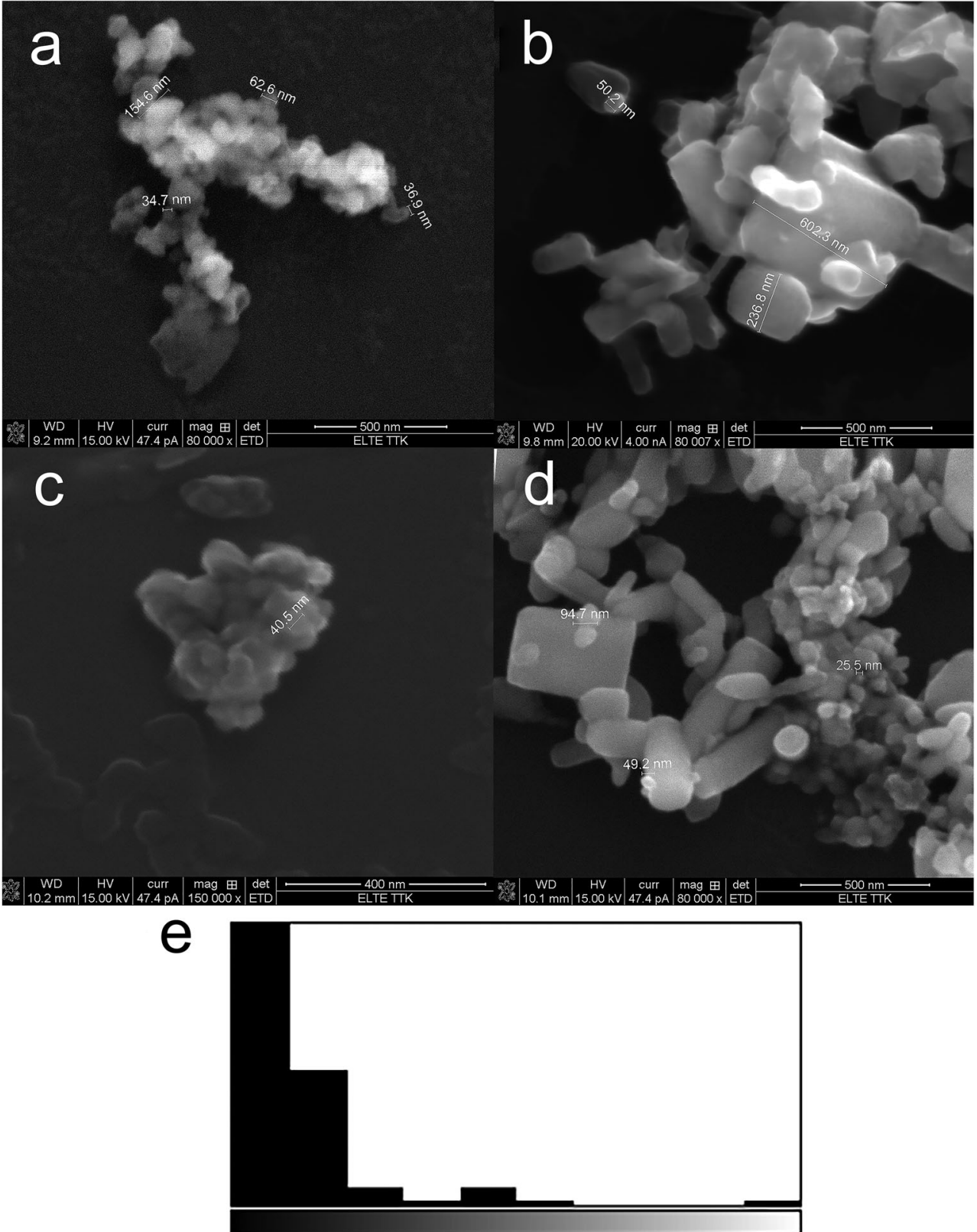

29.268

Count: 100

Mean: 130.221

StdDev: 118.335

Bins: 10
877.073

Min: 29.268

Max: 877.073

Mode: 29.268 (60)

Bin Width: 84.780 significantly change the size or morphology of the materials (Fig. 1a, b, c, d). Coating around the materials by the NAC was not visible by SEM.

\section{Zinc ion dissolution}

There was no significant difference in the complex $\mathrm{Zn}^{2+}$ dissolution associated with mitigation studies between the two pure $\mathrm{ZnO}$ particles of different sizes (Table 1). On the other
Table 1 The dissolution of $15 \mathrm{~nm} \mathrm{ZnO,} 140 \mathrm{~nm} \mathrm{ZnO}$, and the mixture (pure and with the addition of NAC) (mg/l)

Zinc dissolution (mg/l—from 10.04 mg/l Zn-)

\begin{tabular}{llll}
\hline & $15 \mathrm{~nm} \mathrm{ZnO}$ & $140 \mathrm{~nm} \mathrm{ZnO}$ & Mixture \\
\hline Pure & $4.13 \pm 0.01$ & $4.31 \pm 0.09$ & $5.78 \pm 0.07$ \\
Addition of NAC & $5.87 \pm 0.05$ & $5.30 \pm 0.05$ & $6.01 \pm 0.04$ \\
\hline
\end{tabular}


hand, significantly more zinc ions $(\sim 30-40 \%)$ were dissolved from the binary mixture of the two substances $\left(\mathrm{GLS}_{\mathrm{DF}: 2.6}, 15\right.$ $\mathrm{nm}, t=40.42, p<0.001 ; 140 \mathrm{~nm}, t=22.33, p<0.001)$. The measured data did not follow normal distribution $(W=0.80 ; p$ $<0.05$ ). An increase in zinc dissolution was also observed with the addition of NAC to all test materials ( 15 and $140 \mathrm{~nm} \mathrm{ZnO,}$ 20-30\%; mixture, $4 \%$ ). There was a significant difference for $15 \mathrm{~nm}\left(\mathrm{GLS}_{\mathrm{DF}: 2.6}, t=-58.10, p<0.001\right)$ and $140 \mathrm{~nm} \mathrm{ZnO}$ $\left(\mathrm{GLS}_{\mathrm{DF}: 2.6}, t=-16.65, p<0.001\right)$ and a less prominent but also significant difference for the mixture $\left(\mathrm{GLS}_{\mathrm{DF}: 2.6}, t=-4.04\right.$, $p<0.05)$ compared with the dissolution values of untreated pairs of materials. Furthermore, in all cases, significant difference was found between the NAC-treated compounds $\left(\mathrm{GLS}_{\mathrm{DF}: 2.6}, 15 \mathrm{~nm}\right.$ vs. $140 \mathrm{~nm}, t=13.96, p<0.001 ; 15$ vs. Mix, $t=2.77, p<0.05 ; 140 \mathrm{~nm}$ vs. Mix, $t=15.28, p<0.001$ ). For the $15 \mathrm{~nm}$ and the mixture, this difference was relatively slight $(\sim 3 \%)$.

\section{The mitigation effect of $\mathrm{N}$-acetylcysteine and toxicity of $\mathrm{ZnCl}_{2}$ compared with $\mathrm{ZnO}$ NPs on Panagrellus redivivus}

The addition of NAC significantly reduced the toxic effects of $\left.15 \mathrm{~nm} \mathrm{ZnO} \mathrm{(GLS} \mathrm{DF}_{\mathrm{D}: 4.60}, t=-4.44, p<0.001\right)$ (Fig. 2a). In the case of $140 \mathrm{~nm} \mathrm{ZnO}$, a slight mitigating effect was observed $\left(\mathrm{GLS}_{\mathrm{DF}: 4.56}, t=-3.34, p<0.05\right)$ (Fig. $\left.2 \mathrm{~b}\right)$. The mitigating effect showed a decreasing tendency above $2.51 \mathrm{mg} / \mathrm{l}$ and $1.26 \mathrm{mg} / \mathrm{l}$ for $15 \mathrm{~nm}$ and $140 \mathrm{~nm} \mathrm{ZnO}$, respectively. In contrast, when using $\mathrm{ZnCl}_{2}$, mitigation was only observed if the highest concentration $(4.23 \mathrm{mg} / 1 \mathrm{Zn})$ was excluded $\left(\mathrm{LM}_{\mathrm{DF}: 3.44}, t=2.07\right.$, $p<0.05$ ) (Fig. 2c). The two different particle sizes were also
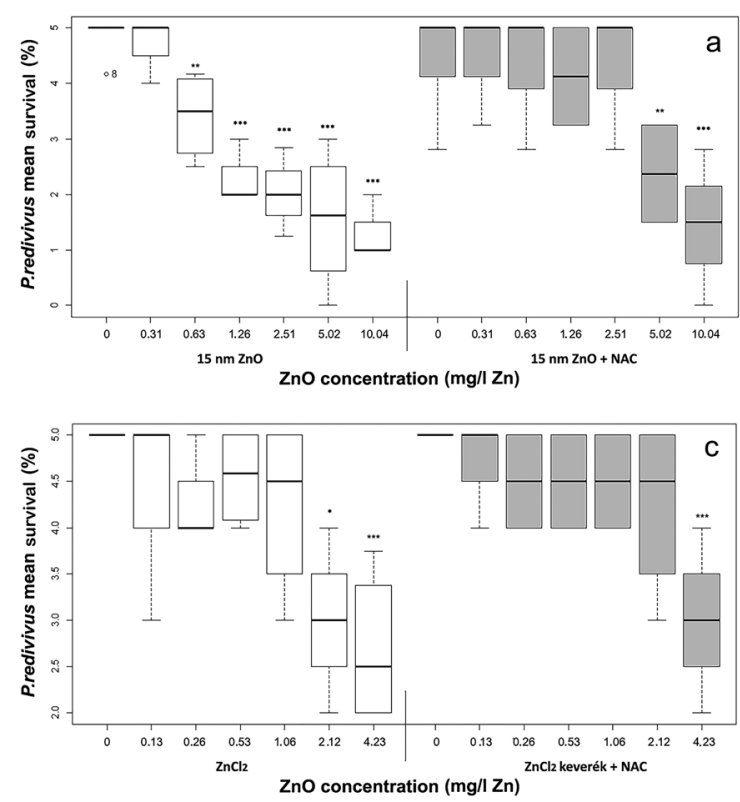

Fig. 2 Mitigating effect of $\mathrm{N}$-acetylcysteine on $P$. redivivus in the presence of $15 \mathrm{~nm} \mathrm{ZnO} \mathrm{(a),} 140 \mathrm{~nm}(\mathbf{b}), \mathrm{ZnCl}_{2}$ (c) and mixture of $15 \mathrm{~nm}+140 \mathrm{~nm} \mathrm{ZnO} \mathrm{(d)} \mathrm{after} 24 \mathrm{~h}$ exposure. Four replicates were affected differently by mitigation treatment. Notwithstanding the two highest concentrations, where none of the substances had a mitigating effect, a greater decrease in toxicity was observed in the presence of $15 \mathrm{~nm} \mathrm{ZnO}$ than at $140 \mathrm{~nm} \mathrm{ZnO}$ $\left(\mathrm{GLS}_{\mathrm{DF}: 4.44}, t=2.09, p<0.05\right)$. These results are also apparent from the $\mathrm{LC}_{50}$ values (Table 2). Our data did not follow normal distribution $(W=0.85 ; p<0.05)$.

When testing the pure materials, no particle size-dependent toxicity was observed. $\mathrm{ZnCl}_{2}$ was significantly less toxic than the two $\mathrm{ZnO}$ particles in the concentration series based on the dissolved zinc content $\left(\mathrm{GLS}_{\mathrm{DF}: 4.56}, 15 \mathrm{~nm}, t=-3.16, p<0.05\right.$; $140 \mathrm{~nm}, t=-3.16, p<0.01$ ) (Fig. 3a).

\section{Interaction between $\mathrm{ZnO}$ nanoparticles}

A synergistic increase in toxicity was observed when using the binary mixture of the two particle-sized $\mathrm{ZnO}$ (Fig. 3a). Compared with the $15 \mathrm{~nm} \mathrm{ZnO}$ particle, the mixture proved to be significantly more toxic, even when used without the addition of NAC $\left(\mathrm{GLS}_{\mathrm{DF}: 4.56}, 15 \mathrm{~nm}, t=2.05, p<0.05\right)$. Moreover, this difference in toxicity was further increased by the addition of NAC. Thus, in that case, the toxic effect of the mixture was stronger than both of the used $\mathrm{ZnO}$ size type alone $\left(\mathrm{GLS}_{\mathrm{DF}: 4.56}, 15 \mathrm{~nm}, t=-3.33, p<0.01 ; 140 \mathrm{~nm}\right.$, $t=-2.50, p<0.01$ ) (Fig. 3b). There was no statistically demonstrable mitigating effect of the antioxidant on the mixture when studying all of the concentrations, although in up to $1.26 \mathrm{mg} / \mathrm{l} \mathrm{Zn}$, a slight decrease in toxicity was observed as compared with the mixture without NAC $\left(\mathrm{GLS}_{\mathrm{DF}: 4.28}\right.$, $t=-2.33, p<0.05$ ) (Fig. 2d). This can also be supported by LOAEC values (pure, $0.31 \mathrm{mg} / 1$; NAC, $1.26 \mathrm{mg} / \mathrm{l}$ ). The
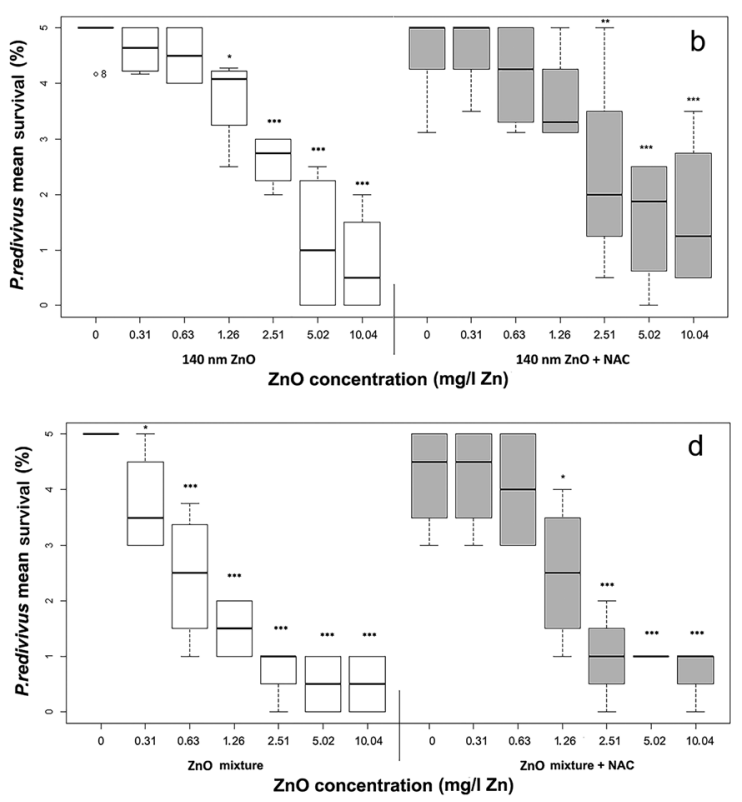

used per concentration. Significance levels: $* p<0.05 ; * * * p<0.001$. Linear model shows the difference between the control $(0 \mathrm{mg} / \mathrm{l})$ and the individual concentrations 
Table $2 \mathrm{LC}_{50}$ values of $15 \mathrm{~nm}$, $140 \mathrm{~nm} \mathrm{ZnO,} \mathrm{ZnCl}_{2}$, and the mixture on Panagrellus redivivus, individually and with the addition of NAC. n.d.: not determined due to the lack of data or mathematical reasons

\begin{tabular}{lllll}
\hline & $15 \mathrm{~nm}$ & $140 \mathrm{~nm}$ & $\mathrm{ZnCl}_{2}$ & Mixture \\
\hline Pure & 1.85 & 2.66 & 4.96 & 0.65 \\
& $(\mathrm{CI} 95 \% 1.1-3.13)$ & $(\mathrm{CI} 95 \% 1.6-4.53)$ & $(\mathrm{CI} 95 \%$ n.d. $)$ & $(\mathrm{CI} 95 \%$ n.d. $)$ \\
Addition of NAC & 14.091 & 10.725 & 5.80 & 1.62 \\
& (CI 95\% n.d.) & (CI 95\% n.d.) & (CI 95\% n.d.) & (CI 95\% n.d.) \\
\hline
\end{tabular}

mitigating effect was less evident for the mixture than for the two $\mathrm{ZnO}$ particles alone, as can be seen from the $\mathrm{LC}_{50}$ values (Table 2).

\section{Evaluation of reactive oxygen species generation method}

The newly developed method was repeated six times to make sure it was functional. In 5 out of 6 experiments, the ROS content was between 0.374 and $0.425 \mu \mathrm{M} / \mathrm{mg}$ in the Milli-Q water control groups. A peak value of $0.716 \mu \mathrm{M} / \mathrm{mg}$ was experienced only in one case. Control values per treatment are shown in Table 3. When comparing the Milli-Q water control values, SD was 0.018 and CV $4.6 \%$, excluding the peak value with outlier analysis by graphic representation $(0.716 \mu \mathrm{M} / \mathrm{mg}$ ) (see Appendix A for Q-Q plot).

\section{Measuring the intracellular reactive oxygen species generation}

Among the three measured pure materials, the highest ROS production was observed for the mixture and the lowest for the
Fig. 3 The toxic effect of $15 \mathrm{~nm}$ $\mathrm{ZnO}, 140 \mathrm{~nm} \mathrm{ZnO}, \mathrm{ZnCl}_{2}$, and the mixture of $15 \mathrm{~nm}+140 \mathrm{~nm}$ $\mathrm{ZnO}$ on $P$. redivivus after $24 \mathrm{~h}$ exposure time without (a $15 \mathrm{~nm}$, empty square; $140 \mathrm{~nm}$, empty diamond; mixture, empty triangle; $\mathrm{ZnCl}_{2}$, multiplication sign) and with (b $15 \mathrm{~nm}$, filled square; $140 \mathrm{~nm}$, filled diamond; mixture, filled triangle; $\mathrm{ZnCl}_{2}$, squared times) the addition of NAC. In the $\mathrm{ZnCl}_{2}$ assay, the concentration series were set based on the dissolved ions (from $10.04 \mathrm{mg} / \mathrm{l} \mathrm{Zn}$; on average 4.23 $\mathrm{mg} / \mathrm{Zn}$ ). The points were calculated based on the dissolution for the given concentration in the figure. Thus, for each treatment: $0.31-0.13 ; 0.63-0.26 ; 1.26-0.53$; $2.51-1.06 ; 5.02-2.12$ and 10.04 $4.23 \mathrm{mg} / \mathrm{Z} \mathrm{Zn}$. Four replicates per concentration were used
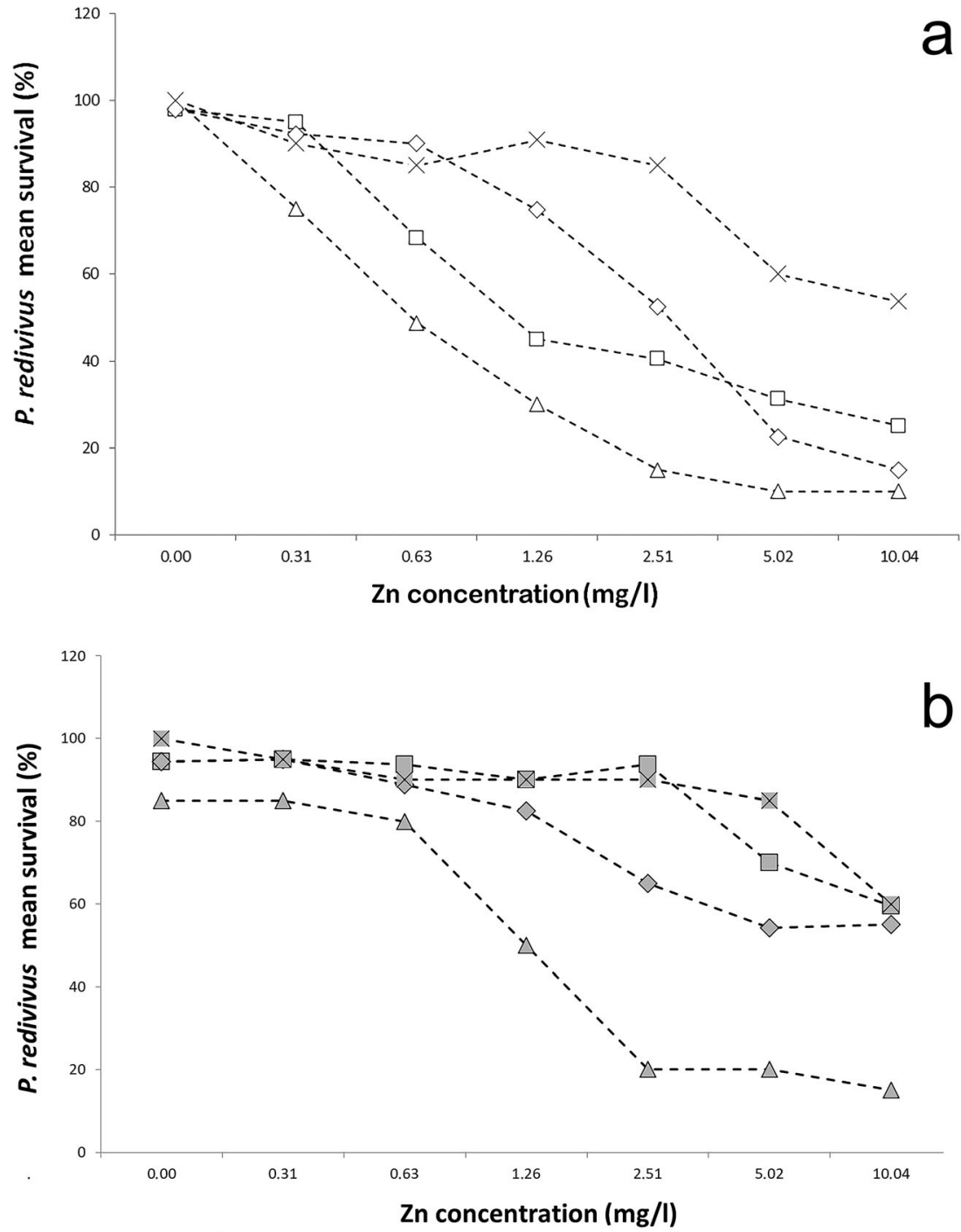
Table 3 Measured ROS $(\mu \mathrm{M} / \mathrm{mg})$ control values

\begin{tabular}{llll}
\hline & $15 \mathrm{~nm}$ & $140 \mathrm{~nm}$ & Mixture \\
\hline Pure & 0.698 & 0.380 & 0.399 \\
& 0.734 & 0.374 & 0.420 \\
Addition of NAC & 0.399 & 0.425 & 0.425 \\
& 0.420 & 0.415 & 0.415 \\
\hline
\end{tabular}

The peak values were indicated in italics

$140 \mathrm{~nm} \mathrm{ZnO} \mathrm{(Table} \mathrm{4).} \mathrm{Therefore,} 140 \mathrm{~nm} \mathrm{ZnO}$ was significantly different from the mixture $\left(\mathrm{LM}_{\mathrm{DF}: 3.8}, t=8.930\right.$, $p<0.001)$ and $15 \mathrm{~nm} \mathrm{ZnO}\left(\mathrm{LM}_{\mathrm{DF}: 3.8}, t=5.322, p<0.01\right)$ (Fig. $4 a)$. A concentration-dependent ROS increase and a significant difference were observed in the case of $15 \mathrm{~nm} \mathrm{ZnO}$ and the binary mixture $\left(\mathrm{LM}_{\mathrm{DF}: 3.8}, t=4.440, p<0.01\right)$. In the presence of NAC, a completely different tendency was observed from when the materials were applied alone (Table 5), as there was no significant difference between the materials (Fig. 4b). Both for $140 \mathrm{~nm} \mathrm{ZnO}$ and the mixture, a sharp increase in ROS production was observed at $2.51 \mathrm{mg} / \mathrm{Zn}$ concentration, followed by a substantial decrease. For the data obtained during the reactive oxygen species measurement, a normal distribution was observed $(W=0.94 ; p>0.05)$.

\section{Discussion}

\section{The mitigation effect of $\mathrm{N}$-acetylcysteine on Panagrellus redivivus}

So far, the mitigating effect of $\mathrm{N}$-acetylcysteine on nano-metal oxides has been demonstrated mainly in a human cell test system (Wang et al. 2014, Liu et al. 2017, El-Shorbagy et al. 2019). Wu et al. (2013) have shown the mitigation effect of NAC $(5 \mathrm{mM})$ on ZnO NPs $(50 \mu \mathrm{g} / \mathrm{l})$ in another nematode test species. Their results were comparable with our findings. We also experienced $20 \%$ mitigation in $0.63 \mathrm{mg} / \mathrm{l}$ concentration in the case of $15 \mathrm{~nm} \mathrm{ZnO}$ on the nematode $P$. redivivus, similarly as stated in $\mathrm{Wu}$ et al. (2013). In higher concentrations (1.26$10.04 \mathrm{mg} / \mathrm{l} \mathrm{Zn}$ ), NAC successfully reduced the toxic effects of both $15 \mathrm{~nm}$ and $140 \mathrm{~nm} \mathrm{ZnO}$ particles on average by $50 \%$ and $30 \%$, respectively.

Particle size-dependent mitigation is less known since bulk controls were lacking in most studies (Wang et al. 2014, Yang and Ma 2014, El-Shorbagy et al. 2019). Liu et al. (2017) compared the effects of two nano-sized $\mathrm{ZnO}$ particles (18.5 $\pm 1.2 \mathrm{~nm}$ and $47.1 \pm 5.1 \mathrm{~nm} \mathrm{ZnO}$ ) on the human neuroblastoma SHSY5Y cell line. When tested alone, they found stronger toxic effects from the smaller particle size $\mathrm{ZnO}$, and the addition of NAC reduced the toxicity of both particle sizes. Mitigation was the strongest at concentrations below $40 \mathrm{mg}$ /

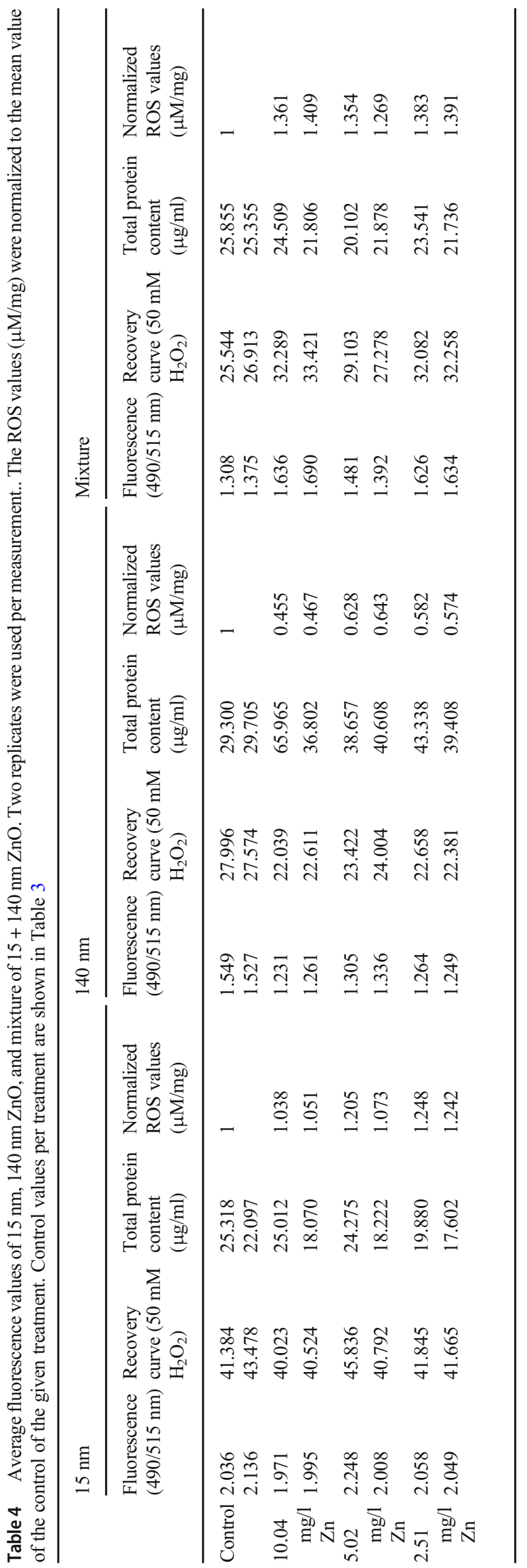




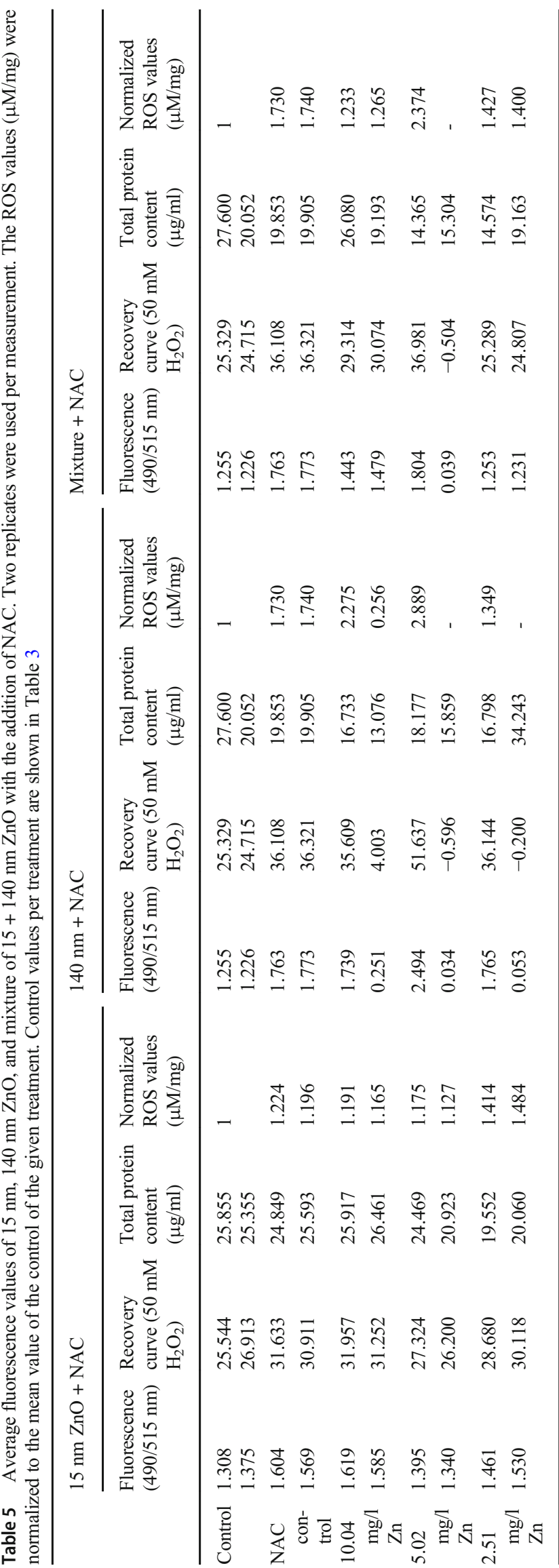

1, above which a reduced effect was observed, as well as a slight difference in toxicity between the two particle sizes. In the case of the larger particle size, the mitigation was smaller, similarly to present studies, where a milder effect was observed in the case of $140 \mathrm{~nm} \mathrm{ZnO}$. These results are supported by our earlier findings where we found $140 \mathrm{~nm} \mathrm{ZnO}$ to be more toxic in the presence of soil solution (to the nematode P. redivivus) and artificial soil (to the springtail Folsomia candida) (Kiss et al. 2018). From the two substances applied in our study, the larger particle size toxicity was more difficult to mitigate by the NAC. This is presumably because the two materials had different surface charge densities, distributions, and electrical potentials due to their different size (Abbas et al. 2008, Holmberg et al. 2013) as well as different morphology (Andelman 1995).

Liu et al. (2017) also compared the effects of nano and bulk $\mathrm{ZnO}$ with $\mathrm{ZnCl}_{2}$ similarly to our experiments. Although mitigation was observed in this case at two lower concentrations (122.9 $\mu \mathrm{M}$ and $245.7 \mu \mathrm{M} \mathrm{ZnCl}_{2}$ ), above this, cell survival rate decreased below $10 \%$ even with the addition of NAC. Therefore, NAC had a much weaker effect on $\mathrm{ZnCl}_{2}$ than on the nanoforms, similarly to our results. According to the present experiments, NAC has a lower effect on ionic toxicity.

No specific reference has been found regarding the effect of $\mathrm{N}$-acetylcysteine on the dissolution of $\mathrm{Zn}$, but the chelating properties of the material have been described in several studies (Rossignol 2005, Flora and Pachauri 2010, Giampreti et al. 2016). Solubility values in the present study were significantly higher when NAC was added, as here the total $\mathrm{Zn}$ content was measured. While from the two tested $\mathrm{ZnO}$ particles alone, approximately the same amount of $\mathrm{Zn}$ dissolved, after the addition of NAC, significantly lower values were obtained from $\mathrm{ZnO}$ with the larger particle size. Our experiments have shown that $N$-acetylcysteine addition reduces the toxicity of 15 and $140 \mathrm{~nm} \mathrm{ZnO}$ particles on $P$. redivivus.

Based on our test results, NAC can be favorable as mitigation agent; however, before the environmental applications, the effects of NAC require more research with relevant test systems.

\section{Elucidate the role of ionic toxicity in the toxicity mechanism of ZnO NPs}

The concentrations of $\mathrm{ZnCl}_{2}$ used in these experiments represented the amount of dissolved $\mathrm{Zn}$ ions present in the test system. It can be seen that behind the toxic effects of $\mathrm{ZnO}$ particles, there could be additional properties apart from the toxicity of dissolved ions, like spontaneous and size relevant ROS generation and interaction between the cell and the particle. These results are in agreement with the findings of Song et al. (2010) who showed that the amount of $\mathrm{Zn}^{2+}$ dissolved and the amount of ROS generated could not induce the degree of cytotoxicity that was observed. Thus, it is assumed 
Fig. 4 The mean amount of generated reactive oxygen radical ( $\mu \mathrm{M} / \mathrm{mg}$ ) by $15 \mathrm{~nm}, 140 \mathrm{~nm}$, and the mixture without (a) and with (b) the addition of NAC (15 nm, empty square; $140 \mathrm{~nm}$, empty diamond; mixture, empty triangle). Two replicates per concentration were used $(15 \mathrm{~nm}$, filled square; $140 \mathrm{~nm}$, filled diamond; mixture, filled triangle)
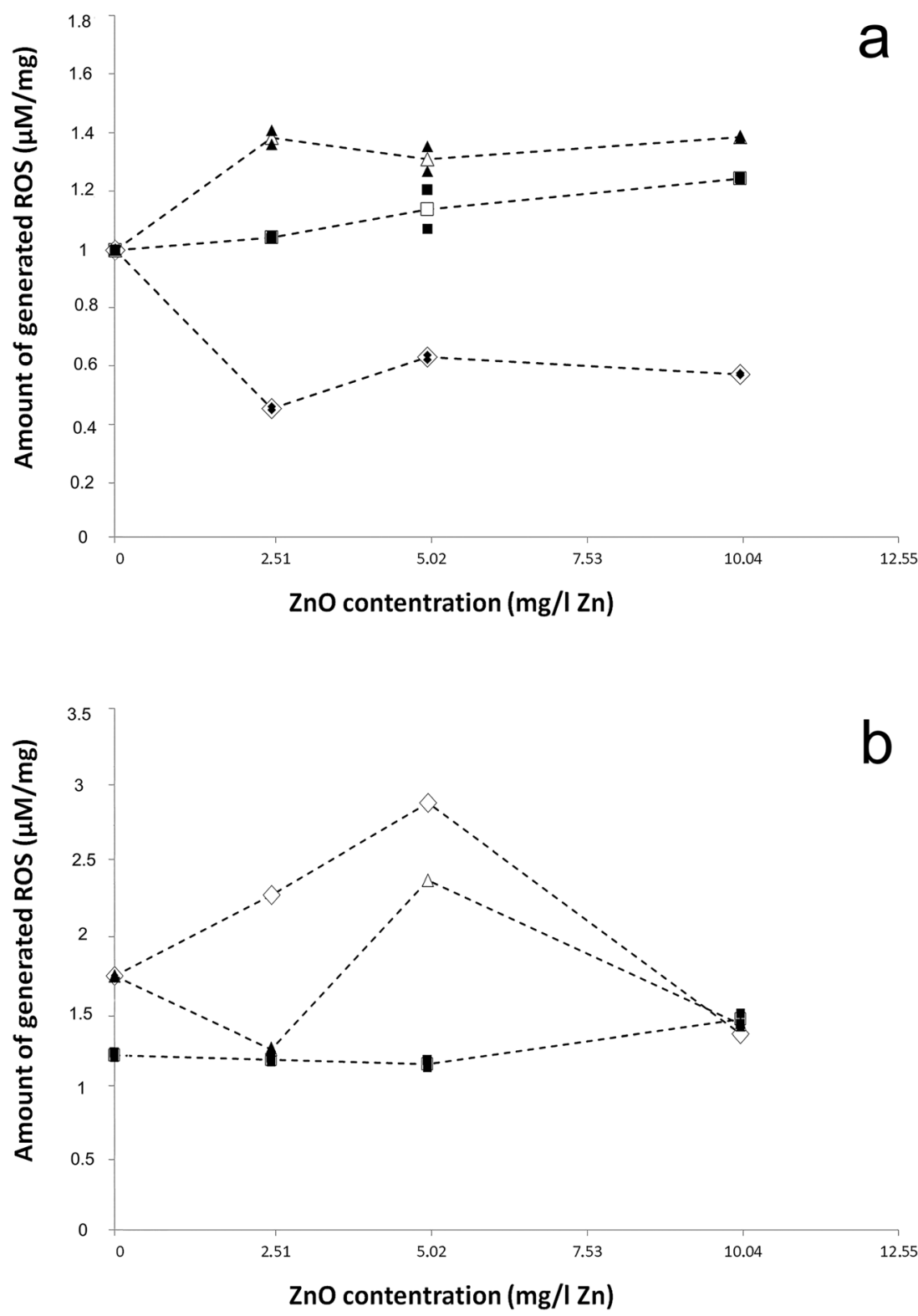

that additional toxicity factors must be present to produce the observed effects.

\section{Synergistic toxicity increases due to mixing the $\mathrm{ZnO}$ particles}

Studies have also shown an increase in synergistic toxicity when mixing two different nanomaterials, e.g., ZnO NP + AG NP (Jafari et al. 2011), Au NP+ Pt NP (Mott et al. 2007), and $\mathrm{Ag} \mathrm{NP}+\mathrm{TiO}_{2} \mathrm{NP}$ (Li et al. 2011). However, a reduction in toxicity was detected when nanoparticulate $\mathrm{ZnO}$ and $\mathrm{TiO}_{2}$ were mixed, and this effect was explained by the $\mathrm{Zn}^{2+}$ adsorption on the $\mathrm{TiO}_{2}$ surface and thus became less available for test animals (Tong et al. 2014). In the present study, the binary mixture of two different particle sizes $\mathrm{ZnO}$ showed a substantial increase in toxicity, in the $\mathrm{Zn}$ dissolution rate and the ROS production. The increase in toxicity was also observed with the addition of $N$-acetylcysteine, as the lowest mitigating effect was detected in the case of the mixture. There is no literature available on testing mixture toxicity with the addition of NAC. According to Liu et al. (2017) and the present experiments with NAC, the antioxidant has less influence on the toxic effects caused by dissolved ions. The measured amount of dissolved ions was 1.5 times higher in the mixture than in the two substances individually. This could be one reason behind the milder mitigation effect on the mixture.

SEM images of the mixture compared with the pure compounds images (Kiss et al. 2018) confirm that both materials are present in the new mixture and a new $\mathrm{ZnO}$ with an average particle size between the two other materials $(130 \pm 118 \mathrm{~nm})$, 
with both spherical and irregular particles, has been generated. Particle distributions also show that approximately $30 \%$ of the particles found in the $140 \mathrm{~nm} \mathrm{ZnO}$ are in the nano-size range (37-97 nm, most often $37 \mathrm{~nm}$ ) (Kiss et al. 2018), so the ratio of nanoparticles has increased above $50 \%$ due to the mixing of the two materials. Moreover, larger particles are believed to have a dispersing effect on the test system. In the mixture, particles aggregated more with each other-due to the different charge distribution - than with particles of their size group. As a result, small particles aggregated on the surface of $140 \mathrm{~nm} \mathrm{ZnO}$ particles fixed the large surface, increasing dissolution, reactivity, and thus toxicity. This is also probably because of the different surface properties (Abbas et al. 2008, Holmberg et al. 2013) and morphology (Andelman 1995). Therefore, by mixing the particles, the different adverse effects of the two materials (15 nm-particle size, $140 \mathrm{~nm}$ irregular morphology) reinforce each other, which may be the reason for the stronger toxic effects.

\section{Evaluation of reactive oxygen species generation method}

The method suggested by literature proved to be unsuitable for measuring the produced ROS in our test system. Sarasija and Norman (2018) recommend removing supernatant from above the animal with $100 \mu \mathrm{l}$ of liquid remaining in the tubes. This is not feasible since the amount of liquid remaining in the Eppendorf tube cannot be accurately determined. Even though animals settle to the bottom of the tube, for such a small amount, it is inevitable to enter the pipette. Yoon et al. (2018), on the other hand, suggests a more feasible method by pipetting the animals onto a glass slide. However, the recommended volume of $10 \mu \mathrm{l}$ was very low for the 40 animals used in our experiments. As based on our own experience, the animals can be moved with $80 \mu \mathrm{l}$ of liquid. In both protocols and Wang et al. (2018) suggest adding an indicator to the sample after lysis, but in our tests, it was found that too much time elapses between incubation and measurement. Consequently, animals still alive can degrade the produced reactive oxygen species. The APF was added immediately after the test end and lysed with, thus preventing the breakdown of ROS. After these changes, the method became usable, and protein and fluorescence measurements of the samples were successful.

During the method development, we managed to modify the ROS measurements described by Sarasija and Norman (2018), Wang et al. (2018), and Yoon et al. (2018), so they would be usable and reproducible with the test species and indicator material used in the present study. Without improvements, we failed to use the method. Subsequently, we applied the refined method successfully several times. In the future, it can be used to measure the induced intracellular reactive oxygen species with APF indicator in the $P$. redivivus and probably in comparable test species.

\section{Testing reactive oxygen species production}

Concentration-dependent production of reactive oxygen species is generally detected in ZnO NPs assays (Xia et al. 2008, Song et al. 2010, Liu et al. 2017, Huang et al. 2019). Compared with other metal oxides, $\mathrm{H}_{2} \mathrm{O}_{2}$ production is medium dependent, but superoxide production was always the highest in the case of ZnO NPs (Xia et al. 2008). In most instances, comparisons of nano and bulk $\mathrm{ZnO}$ were found to have a visible particle size-dependent effect; $\mathrm{ZnO}$ NPs induced higher ROS generation (Song et al. 2010, Liu et al. 2017) than their bulk counterparts. In the present experiments, the highest amount produced was found after $3 \mathrm{~h}$ of exposure time in the mixture, and the lowest appeared in the $140 \mathrm{~nm}$ $\mathrm{ZnO}$. When NAC was added, ROS were produced to a much greater extent in the case of $140 \mathrm{~nm}$ and the mixture than independently. In literature, ROS production is generally reduced by NAC (Wang et al. 2014). It is hypothesized that NAC-induced GSH production has not yet begun during the 3-h ROS exposure (Farbiszewski et al. 2000), so the decrease was not studied. Further experiments should be performed with longer exposure times (6 and $12 \mathrm{~h}$ ).

\section{Summary of discussion}

$P$. redivivus was sensitive to both 15 and $140 \mathrm{~nm} \mathrm{ZnO}$ treatment. Our studies have shown that $N$-acetylcysteine can mitigate the toxic effects of both studied particle sizes. From the applied two particle sizes, $140 \mathrm{~nm} \mathrm{ZnO}$ toxicity was found to be harder to mitigate by NAC. This can be explained by morphological differences (Iswarya et al. 2015, Tong et al. 2015), the difference in charge distribution (Andelman 1995), and the fact that $N$-acetylcysteine was less able to make complexes with this material than with smaller particle-sized one, likely also due to morphological differences. The NAC had less mitigation on the toxic effect of zinc ions (Liu et al. 2017). This was possibly one of the reasons why lower mitigating effects were found in the case of the mixture of the two substances, where the solubility was significantly higher. The $\mathrm{ZnCl}_{2}$ concentrations were used to represent the amount of dissolved $\mathrm{Zn}$ ions present in the test system, which proved that other particle size-dependent toxic effects are also important in $\mathrm{ZnO}$ NP toxicity besides dissolution. Previous findings (Song et al. 2010) are supported by our results. When the two materials were applied in binary mixtures, the toxic effects increased significantly. Besides, the dissolved zinc content and the ROS generation also increased. It is assumed that the chemical and physical properties of the materials (several smaller particles - higher bioavailability, increased toxicity from a fixed, large surface area, morphological aspects) have 
been mutually reinforcing each other to form a much more reactive mixture that is more toxic to $P$. redivivus test organism. Studies have shown that $15 \mathrm{~nm} \mathrm{ZnO}$ alone can generate higher amounts of ROS and dissolved ions than $140 \mathrm{~nm} \mathrm{ZnO}$.

On the other hand, such different trends in toxicity can be changed by influencing some parameters of the test system in order to neutralize the toxic effects of $15 \mathrm{~nm}$ $\mathrm{ZnO}$. This happened in present study when adding NAC as a mitigation agent or in Kiss et al. (2018) when soil solution as an alternative test media was applied. In both cases, $140 \mathrm{~nm} \mathrm{ZnO}$ will immediately become more toxic than its counterpart with a smaller size. This is presumably due to the irregular particle morphology. ROS production was induced by all used materials measured by the modified method. When testing the substances by themselves for ROS production, it was the highest in the mixture and the lowest in the $140 \mathrm{~nm} \mathrm{ZnO}$. With the addition of NAC, due to the low toxicity of the substance itself, the control ROS values were somewhat higher than with the individually tested compounds. Higher exposure times are required for the assay for the substance to exert its effect (Farbiszewski et al. 2000).

\section{Conclusion}

Our findings testify the need to investigate the mechanism behind $\mathrm{ZnO}$ nanoparticles toxicity. Toxicity mitigation by special antioxidants is a new way to decrease the environmental risk of nanoparticles. As proved by our study, $\mathrm{N}$ acetylcysteine can mitigate the effect of ZnO NPs on nematodes. It is also important to investigate the same compound in different test systems, as only one way of testing can lead to false assumptions. In the present study, we only experienced size related toxicity difference with the addition of NAC. Moreover, our findings highlight the role of dissolution unrelated ROS production in toxicity. Our study suggests taking into consideration the interaction between compounds as a hazard and risk assessment for nanomaterials. Future studies need to focus more on morphology and charge density distribution of the researched nanomaterials.

Supplementary Information The online version contains supplementary material available at https://doi.org/10.1007/s11356-021-12674-7.

Acknowledgements We would like to express our thanks to Eötvös Loránd University, Central Research and Instrument Center for their help with scanning electron microscopy and to the Department of Chemistry at Szent István University for their help with inductively coupled plasma atomic emission spectroscopy. Special thanks are due to Professors Zoltán Hórvölgyi, Miklós Mézes, and Gábor Bakonyi for their advice.
Author contribution All authors contributed to the study conception and design. Material preparation, data collection, and analysis were performed by Kiss, L.V. Besides Kiss. L.V., Sávoly, Z., and Ács, A. took part in the method development, and Ács, A. also took part in the measuring process of the produced reactive oxygen species. Seres, A. and Nagy, P. I. coordinated and supervised the whole research process. The first draft of the manuscript was written by Kiss, L.V., and all authors commented on previous versions of the manuscript. All authors read and approved the final manuscript.

Funding Open access funding provided by Szent István University. This study was supported by the New National Excellence Program under Grant (ÚNKP-18-3-III-SZIE-7) and by 2017-1.3.1-VKE-2017-00001 grant.

Data availability The data that support the findings of this study are available online (https://doi.org/10.6084/m9.figshare.12933284.v1) and from the corresponding author (lolavirag.kiss@gmail.com).

\section{Declarations}

Ethics approval and consent to participate Research involving invertebrates, like nematodes, does not require ethical approval from the ethics committee. Consent to participate is not applicable.

Consent for publication Not applicable.

Competing interests The authors declare that they have no competing interests.

\section{References}

Abbas Z, Labbez C, Nordholm S, Ahlberg E (2008) Size-dependent surface charging of nanoparticles. J Phys Chem 112:5715-5723. https://doi.org/10.1021/jp709667u

Andelman D (1995) Electrostatic properties of membranes: the PoissonBoltzmann theory. In R Lipowsky, E Sackmann (eds) Handbook of biological physics. Elsevier, pp 603-642

Bhatti J, Nascimento B, Akhtar U, Rhind SG, Tien H, Nathens A, and da Luz LT (2018) Systematic review of human and animal studies examining the efficacy and safety of $\mathrm{N}$-acetylcysteine (NAC) and N-acetylcysteine amide (NACA) in traumatic brain injury: impact on neurofunctional outcome and biomarkers of oxidative stress and inflammation. Front Neurol 8: https://doi.org/10.3389/fneur.2017.00744

Brunner TJ, Wick P, Manser P, Spohn P, Grass RN, Limbach LK, Bruinink A, Stark WJ (2006) In vitro cytotoxicity of oxide nanoparticles: comparison to asbestos, silica, and the effect of particle solubility. Environ Sci Technol 40:4374-4381. https://doi.org/10.1021/es052069i

Coll C, Notter D, Gottschalk F, Sun T, Som C, Nowack B (2016) Probabilistic environmental risk assessment of five nanomaterials (nano-TiO2, nano$\mathrm{Ag}$, nano-ZnO, CNT, and fullerenes). Nanotoxicology 10:436-444. https://oi.org/10.3109/17435390.2015.1073812

Desta IT, Al-Sharif A, AlGharibeh N, Mustafa N, Orozaliev A, Giakoumidis N, Gunsalus KC, Song YA (2017) Detecting and trapping of a single C. elegans worm in a microfluidic chip for automated microplate dispensing. SLAS Technol 22:431-436. https://doi. org/10.1177/2211068216669688

El-Shorbagy HM, Eissa SM, Sabet S, El-Ghor AA (2019) Apoptosis and oxidative stress as relevant mechanisms of antitumor activity and genotoxicity of zno-NPs alone and in combination with N-acetyl cysteine in tumor-bearing mice. Int J Nanomedicine 14:39113928. https://doi.org/10.2147/IJN.S204757 
Farbiszewski R, Witek A, Skrzydlewska E (2000) N-acetylcysteine or trolox derivative mitigate the toxic effects of methanol on the antioxidant system of rat brain. Toxicology 156:47-55. https://doi.org/ 10.1016/S0300-483X(00)00333-4

Flora SJS, Pachauri V (2010) Chelation in metal intoxication. Int J Environ Res Public Health 7:2745-2788. https://doi.org/10.3390/ ijerph7072745

Giampreti A, Lonati D, Ragghianti B, Ronchi A, Petrolini VM, Vecchio S, Locatelli CA (2016) N-acetyl-cysteine as effective and safe chaleting agent in metal-on-metal hip-implanted patiens: two cases. Case Rep Orthop 2016:1-7

Gottschalk F, Sonderer T, Scholz RW, Nowack B (2009) Modeled environmental concentrations of engineered nanomaterials $(\mathrm{TiO} 2, \mathrm{ZnO}$, $\mathrm{Ag}, \mathrm{CNT}$, fullerenes) for different regions. Environ Sci Technol 43: 9216-9222. https://doi.org/10.1021/es9015553

Holmberg JP, Ahlberg E, Bergenholtz J, Hassellöv M, Abbas Z (2013) Surface charge and interfacial potential of titanium dioxide nanoparticles: experimental and theoretical investigations. J Colloid Interface Sci 407:168-176. https://doi.org/10.1016/j.jcis.2013.06. 015

Hrács K, Sávoly Z, Seres A, Kiss LV, Papp IZ, Kukovecz Á, Záray G, Nagy P (2018) Toxicity and uptake of nanoparticulate and bulk $\mathrm{ZnO}$ in nematodes with different life strategies. Ecotoxicology 27:10581068. https://doi.org/10.1007/s10646-018-1959-8

Huang C-WW, Li S-WW, Liao VH-CC (2019) Long-term sediment exposure to $\mathrm{ZnO}$ nanoparticles induces oxidative stress in Caenorhabditis elegans. Environ Sci Nano 6:2602-2614. https:// doi.org/10.1039/c9en00039a

Iswarya V, Bhuvaneshwari M, Ann S, Iyer S, Chaudhuri G, Chandrasekaran PT, Bhalerao GM, Chakravarty S, Raichur AM, Chandrasekaran $\mathrm{N}$ et al (2015) Combined toxicity of two crystalline phases (anatase and rutile) of Titania nanoparticles towards freshwater microalgae: Chlorella sp. Aquat Toxicol 161:154-169. https:// doi.org/10.1016/j.aquatox.2015.02.006

Jafari A, Ghane M, Arastoo S (2011) Synergistic antibacterial effects of nano zinc oxide combined with silver nanocrystales. Afr J Microbiol Res 5:5465-5473. https://doi.org/10.5897/AJMR11.392

Khare P, Sonane M, Pandey R, Ali S, Gupta KC, Satish A (2011) Adverse effects of $\mathrm{TiO} 2$ and $\mathrm{ZnO}$ nanoparticles in soil nematode, Caenorhabditis elegans. J Biomed Nanotechnol 7:116-117. https:// doi.org/10.1166/jbn.2011.1229

Khare P, Sonane M, Nagar Y, Moin N, Ali S, Gupta KC (2014) Size dependent toxicity of zinc oxide nano-particles in soil nematode Caenorhabditis elegans. Nanotoxicology 5390:1-10. https://doi. org $/ 10.3109 / 17435390.2014 .940403$

Kiss LV, Hrács K, Nagy PI, Seres A (2018) Effects of zinc oxide nanoparticles on Panagrellus redivivus (Nematoda) and Folsomia candida (Collembola) in various test media. Int J Environ Res 12:233243. https://doi.org/10.1007/s41742-018-0086-y

Kiss LV, Boros G, Seres A, Nagy PI (2020) Nano-fémoxidok kulcsfontosságú talajállat csoportokra gyakorolt hatásainak áttekintése [Toxic effects of nanosized metal oxides on soil-living organisms with particular ecological importance - a review]. Állattani Közlemények 105:29-57. https://doi.org/10.20331/ allkoz.2020.105.1-2.29

Lead JR, Batley GE, Alvarez PJJ, Croteau MN, Handy RD, McLaughlin MJ, Judy JD, Schirmer K (2018) Nanomaterials in the environment: behavior, fate, bioavailability, and effects - an updated review. Environ Toxicol Chem 37:2029-2063. https://doi.org/10.1002/etc. 4147

Li M, Noriega-Trevino ME, Nino-Martinez N, Marambio-Jones C, Wang J, Damoiseaux R, Ruiz F, Hoek EMV (2011) Synergistic bactericidal activity of Ag-TiO2 nanoparticles in both light and dark conditions. Environ Sci Technol 45:8989-8995

Li Y, Yu S, Wu Q, Tang M, Pu Y, Wang D (2012) Chronic Al2O3nanoparticle exposure causes neurotoxic effects on locomotion behaviors by inducing severe ROS production and disruption of ROS defense mechanisms in nematode Caenorhabditis elegans. J Hazard Mater 219-220:221-230. https://doi.org/10.1016/j.jhazmat. 2012.03.083

Liu J, Kang Y, Yin S, Song B, Wei L, Chen L, Shao L (2017) Zinc oxide nanoparticles induce toxic responses in human neuroblastoma SHSY5Y cells in a size-dependent manner. Int J Nanomedicine 12:8085-8099. https://doi.org/10.2147/IJN.S149070

Ma H, Kabengi NJ, Bertsch PM, Unrine JM, Glenn TC, Williams PL (2011) Comparative phototoxicity of nanoparticulate and bulk $\mathrm{ZnO}$ to a free-living nematode Caenorhabditis elegans: the importance of illumination mode and primary particle size. Environ Pollut 159: 1473-1480. https://doi.org/10.1016/j.envpol.2011.03.013

Ma H, Williams PL, Diamond SA (2013) Ecotoxicity of manufactured $\mathrm{ZnO}$ nanoparticles. A review. Environ Pollut 172:76-85. https://doi. org/10.1016/j.envpol.2012.08.011

Ma H, Wallis LK, Diamond S, Li S, Canas-Carrell J, Parra A (2014) Impact of solar UV radiation on toxicity of $\mathrm{ZnO}$ nanoparticles through photocatalytic reactive oxygen species (ROS) generation and photo-induced dissolution. Environ Pollut 193:165-172. https://doi.org/10.1016/j.envpol.2014.06.027

Maguire SM, Clark CM, Nunnari J, Pirri JK, Alkema MJ (2011) The C. elegans touch response facilitates escape from predacious fungi. Curr Biol 21:1326-1330. https://doi.org/10.1016/j.cub.2011.06.063

Mahmoudi GA, Astaraki P, Mohtashami AZ, Ahadi M (2015) Nacetylcysteine overdose after acetaminophen poisoning. Int Med Case Rep J 8:65-69. https://doi.org/10.2147/IMCRJ.S74563

Microsoft Corporation (2010) Microsoft Excel (No. 2010)

Mott D, Luo J, Njoki PN, Lin Y, Wang L, Zhong C (2007) Synergistic activity of gold-platinum alloy nanoparticle catalysts. Catal Today 122:378-385. https://doi.org/10.1016/j.cattod.2007.01.007

Nagano T (2009) Bioimaging probes for reactive oxygen species and reactive nitrogen species. J Clin Biochem Nutr 45:111-124

Nowacka M, Rygała A, Kręgiel D, Kowalewska A (2018) Poly(silsesquioxanes) and poly(siloxanes) grafted with Nacetylcysteine for eradicating mature bacterial biofilms in water environment. Colloids Surf B: Biointerfaces 172:627-634. https://doi. org/10.1016/j.colsurfb.2018.09.017

Palikaras K and Tavernarakis N (2013) Caenorhabditis elegans (Nematode). In Brenner's encyclopedia of genetics: second edition (vol. 1). Elsevier Inc. https://doi.org/10.1016/B978-0-12-374984-0. 00186-8

RCoreTeam (2013) R: a language and environment for statistical computing. R Foundation for Statistical Computing. Vienna, Austria. ISBN 3-900051-07-0

Rossignol DA (2005) The use of N-acetylcysteine as a chelator for metal toxicity. In: RE Frye \& M Berk (eds) The therapeutic use of Nacetylcysteine (NAC) in medicine, 1st edn. ADIS, pp 169-179 https://doi.org/10.1007/978-981-10-5311-5

Sarasija S, Norman KR (2018) Measurement of ROS in Caenorhabditis elegans using a reduced form of fluorescein. Bio Protoc 8:11. https:// doi.org/10.21769/BioProtoc.2800.Measurement

Sautter J, Kaiser H, Focken U, Becker K (2007) Panagrellus redivivus (Linné) as a live food organism in the early rearing of the catfish Synodontis petricola (Matthes). Aquac Res 38:653-659. https://doi. org/10.1111/j.1365-2109.2007.01714.x

Sávoly Z, Hrács K, Oemmer B, Streli C, Záray G, Nagy PI (2016) Uptake and toxicity of nano- $\mathrm{ZnO}$ in the plant-feeding nematode, Xiphinema vuittenezi: the role of dissolved zinc and nanoparticle-specific effects. Environ Sci Pollut Res 23:9669-9678. https://doi.org/10. 1007/s11356-015-5983-4

Setsukinai K, Urano Y, Majima HJ, Chem JB, Kakinuma K, Majima HJ, Nagano T (2003) Development of novel fluorescence probes that can reliably detect reactive oxygen species and distinguish specific species. J Biol Chem 278:3170-3175. https://doi.org/10.1074/jbc. M209264200 
Shi H, Gu Y, Xie Z, Zhou QI, Mao G, Lin X, Liu K, Liu Y, Zou B, Zhao J (2017) Mechanism of N-acetyl-cysteine inhibition on the cytotoxicity induced by titanium dioxide nanoparticles in JB6 cells transfected with activator protein-1. Exp Ther Med 13:3549-3554. https://doi.org/10.3892/etm.2017.4415

Sochová I, Hofman J, Holoubek I (2006) Using nematodes in soil ecotoxicology. Environ Int 32:374-383. https://doi.org/10.1016/j. envint.2005.08.031

Song W, Zhang J, Guo J, Zhang J, Ding F, Li L, Sun Z (2010) Role of the dissolved zinc ion and reactive oxygen species in cytotoxicity of ZnO nanoparticles. Toxicol Lett 199:389-397. https://doi.org/10. 1016/j.toxlet.2010.10.003

Starnes D, Unrine J, Chen C, Lichtenberg S, Starnes C, Svendsen C, Kille P, Morgan J, Baddar ZE, Spear A et al (2019) Toxicogenomic responses of Caenorhabditis elegans to pristine and transformed zinc oxide nanoparticles. Environ Pollut 247:917-926. https://doi.org/ 10.1016/j.envpol.2019.01.077

Sternberg PW, Horvitz HR (1982) Postembryonic nongonadal cell lineages of the nematode Panagrellus redivivus: description and comparison with those of Caenorhabdifis elegans. Dev Biol 205:181205

Sun SY (2010) N-acetylcysteine, reactive oxygen species and beyond. Cancer Biol Ther 9:109-110. https://doi.org/10.4161/cbt.9.2.10583

Sun TY, Bornhöft NA, Hungerbühler K, Nowack B (2016) Dynamic probabilistic modeling of environmental emissions of engineered nanomaterials. Environ Sci Technol 50:4701-4711. https://doi.org/ 10.1021/acs.est.5b05828

Tong T, Fang K, Thomas SA, Kelly JJ, Gray KA, Gaillard JF (2014) Chemical interactions between nano- $\mathrm{ZnO}$ and nano-TiO2 in a natural aqueous medium. Environ Sci Technol 48:7924-7932. https:// doi.org/10.1021/es501168p

Tong T, Wilke CM, Wu J, Thanh CT, Kelly JJ, Gaillard J, Gray KA (2015) Combined toxicity of nano-ZnO and nano-TiO2: from single- to multi-nanomaterial systems. Environ Sci Technol 49: 8113-8123. https://doi.org/10.1021/acs.est.5b02148

TOXRATLIGHT2.08 (n.d.) Software for statistical evaluation of biotests in ecotoxicology. ToxRat Solutions GmbH, Germany, Alsdorf (2.08)
Vinciguerra MT (1979) Role of nematodes in the biological processes of the soil. Bolletino Di Zool 46:363-374. https://doi.org/10.1080/ 11250007909440312

Wang J, Deng X, Zhang F, Chen D, Ding W (2014) ZnO nanoparticleinduced oxidative stress triggers apoptosis by activating JNK signaling pathway in cultured primary astrocytes. Nanoscale Res Lett 9:1-12. https://doi.org/10.1186/1556-276X-9-117

Wang D, Lin Z, Wang T, Yao Z, Qin M, Zheng S, Lu W (2016) Where does the toxicity of metal oxide nanoparticles come from: the nanoparticles, the ions, or a combination of both? J Hazard Mater 308: 328-334. https://doi.org/10.1016/j.jhazmat.2016.01.066

Wang K, Chen S, Zhang C, Huang J, Wu J, Zhou H, Jin L (2018) Enhanced ROS production leads to excessive fat accumulation through DAF- 16 in Caenorhabditis elegans. Exp Gerontol 112: 20-29. https://doi.org/10.1016/j.exger.2018.07.017

Wu Q, Wang W, Li Y, Li Y, Ye B, Tang M, Wang D (2012) Small sizes of TiO2-NPs exhibit adverse effects at predicted environmental relevant concentrations on nematodes in a modified chronic toxicity assay system. J Hazard Mater 243:161-168. https://doi.org/10.1016/ j.jhazmat.2012.10.013

Wu Q, Nouara A, Li Y, Zhang M, Wang W, Tang M, Ye B, Ding J, Wang D (2013) Comparison of toxicities from three metal oxide nanoparticles at environmental relevant concentrations in nematode Caenorhabditis elegans. Chemosphere 90:1123-1131. https://doi. org/10.1016/j.chemosphere.2012.09.019

Xia T, Kovochich M, Liong M, Ma L, Gilbert B, Shi ḰH, Yeh JI, Zink JI, Nel AE (2008) Comparison of the mechanism of toxicity of zinc oxide and cerium oxide nanoparticles based on dissolution and oxidative stress properties. ACS Nano 2:2121-2134

Yang Q, Ma Y (2014) Irradiation-enhanced cytotoxicity of zinc oxide nanoparticles. Int J Toxicol 33:187-203. https://doi.org/10.1177/ 1091581814529168

Yoon DS, Lee M, Cha DS (2018) Measurement of intracellular ROS in Caenorhabditis elegans using $2^{\prime}, 7^{\prime}$-dichlorodihydrofluorescein diacetate. Bio Protoc 8:1-9. https://doi.org/10.21769/BioProtoc.2774

Publisher's note Springer Nature remains neutral with regard to jurisdictional claims in published maps and institutional affiliations. 